\title{
OP43
}

\section{TESTING EXPERIMENTAL METHODS FOR DISCOMFORT GLARE INVESTIGATIONS}

\author{
Matthieu lodice et al.
}

DOI 10.25039/x46.2019.OP43

from

CIE x046:2019

\author{
Proceedings \\ of the \\ 29th CIE SESSION \\ Washington D.C., USA, June 14 - 22, 2019 \\ (DOI 10.25039/x46.2019)
}

The paper has been presented at the 29th CIE Session, Washington D.C., USA, June 14-22, 2019. It has not been peer-reviewed by CIE.

(C) CIE 2019

All rights reserved. Unless otherwise specified, no part of this publication may be reproduced or utilized in any form or by any means, electronic or mechanical, including photocopying and microfilm, without permission in writing from CIE Central Bureau at the address below. Any mention of organizations or products does not imply endorsement by the CIE.

This paper is made available open access for individual use. However, in all other cases all rights are reserved unless explicit permission is sought from and given by the CIE.

CIE Central Bureau

Babenbergerstrasse 9

A-1010 Vienna

Austria

Tel.: +4317143187

e-mail: ciecb@cie.co.at

www.cie.co.at 


\title{
TESTING EXPERIMENTAL METHODS FOR DISCOMFORT GLARE INVESTIGATIONS
}

\author{
lodice, M. ${ }^{1,2}$, Jost, S. ${ }^{2}$, Dumortier, D. ${ }^{2}$ \\ ${ }^{1}$ CEREMA, Department of territories planning, Aix-en-Provence, FRANCE \\ 2 University of Lyon, ENTPE, LGCB, Vaulx-en-Velin, FRANCE \\ matthieu.iodice@cerema.fr
}

DOI $10.25039 / \times 46.2019 .0 P 43$

\begin{abstract}
Discomfort glare has been investigated for more than a century using various experimental methods. Most of them were based on psychophysical procedures and few others relied on physiological measurements as indicators of it. In this paper, we compare some of these methods to determine the most relevant ones to investigate discomfort glare in an indoor environment. With the same experimental set-up, two experiments were led. In the first one, 35 subjects evaluated two glare sources with different spectral power distribution with seven different psychophysical procedures. In the second one, four physiological measurements were recorded for eight subjects while they were illuminated by the same light sources. Based on the repeatability, the limits and the potential biases of each procedure, three psychophysical methods are recommended to evaluate discomfort glare at photopic levels in an indoor lighting environment. None of the tested physiological measurements produced relevant information about the potential discomfort glare perceived in such environment.
\end{abstract}

Keywords: Discomfort glare, experimental procedure, bias, psychophysics, physiology

\section{Motivation, specific objective}

Discomfort glare, defined by the CIE as glare producing discomfort without impairing vision (CIE, 2017), has been investigated for more than a century. However, the physiological mechanisms behind its perception are not yet fully understood. Empirical formulae are used to prevent lighting installations from producing it. The Unified Glare Rating is the official discomfort glare formula from the CIE 117:1995 (CIE, 1995). However, research about discomfort glare continues and other factors are studied, such as the effects of non-uniformity or spectral contents of the glare source (CIE, 2013; Geerdinck et al., 2016). The JTC7 (Discomfort caused by glare from luminaires with a non-uniform source luminance) is currently working on adapting this formula to non-uniform luminance sources.

In the literature, numerous studies investigated discomfort glare using various experimental methods. Most of them were based on psychophysical procedures in which subjects evaluate their own discomfort glare perception. Few others relied on physiological measurements, as indicators of discomfort glare. The aim of this paper is to compare some of these methods and to select the most relevant ones to investigate discomfort glare in indoor environments. For this purpose, we focused on psychophysical procedures in a first experiment, and on physiological measurements in a second one.

\section{Material and methods}

\subsection{Experimental set-up}

The experimental set-up was identical for both experiments. It consisted in a white octagonal windowless room (Figure 1). The background was illuminated by three LED projectors (SourceFour LED, Lustr+ from the ETC Company) producing an indirect white light (white LED only; $C C T=5870 \mathrm{~K} ; \mathrm{Ra}=70 ; \mathrm{x}=0,32 ; \mathrm{y}=0,34$ ). They provided a uniform lighting with a luminance of the walls at $20 \mathrm{~cd} / \mathrm{m}^{2}$, measured from the observer position (photopic conditions). The subjects sat at the center of the room. They were instructed to look at a target located on the wall in front of them at $1.20 \mathrm{~m}$. 


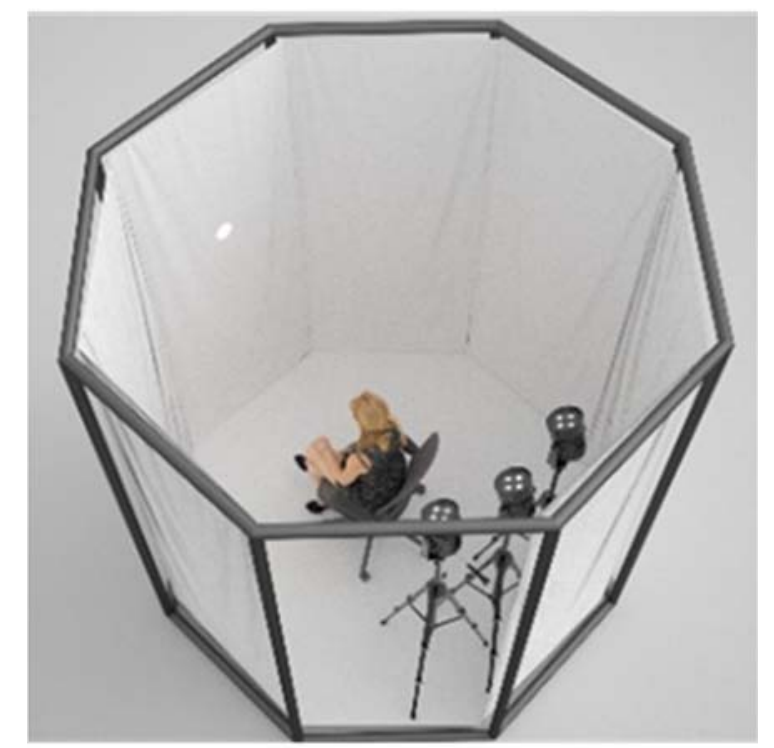

Figure 1 - Simulated image of the experimental room

The circular glare source (diameter $10 \mathrm{~cm}$ ) was located on the front wall, off-centered at $20^{\circ}$ above the subject's line of sight. It was produced by another 7 -channel spectrally tuneable projector (SourceFour LED, Lustr+ from the ETC Company) equipped with a diffuser to avoid non-uniformity. The seven channels were mixed to produce two different glare stimuli. The stimuli were designed to be metameric according to the $\mathrm{CIE} 10^{\circ}$ cone-fundamental observer (CIE, 2018a) and to excite differently melanopsin (CIE, 2018b): HighMel and LowMel. HighMel produced twice as much melanopic radiance than LowMel did.

Figure 2 shows the spectral power distributions (SPDs) of the two stimuli measured from the eye of the observer (diffuser included) and table 1 gives their colorimetric characteristics. Note that the luminance values given in the article are calculated for the $\mathrm{CIE} 10^{\circ}$ cone-fundamental observer with the cone-fundamental luminous efficiency functions $\left(V_{F, 10}\right)(C I E, 2015)$.

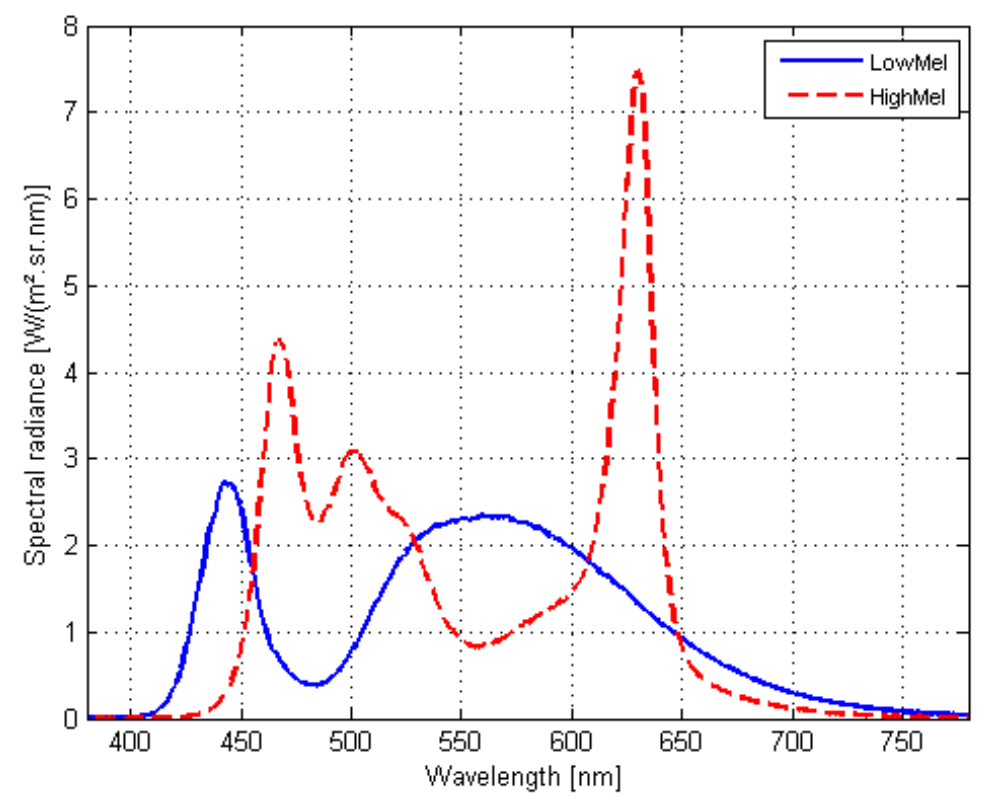

Figure 2 - Spectral radiances of the two glare stimuli 
Table 1 - Colorimetric characteristics of the two glare stimuli

\begin{tabular}{|l|l|l|l|l|l|}
\hline & $\mathrm{X}_{\mathrm{F}, 10}$ & $\mathrm{y}_{\mathrm{F}, 10}$ & $\mathrm{x}$ & $\mathrm{y}$ & $\mathrm{CCT}(\mathrm{K})$ \\
\hline LowMel & 0,36 & 0,36 & 0,35 & 0,36 & 4810 \\
\hline HighMel & 0,36 & 0,36 & 0,37 & 0,34 & 4220 \\
\hline
\end{tabular}

\subsection{Psychophysical experimental procedures}

The comparison of the psychophysical procedures was based on the repeatability of the results and the presence of experimental biases. Seven psychophysical procedures were selected. They can be divided in two categories: absolute and relative evaluations (CIE, 2014).

For absolute evaluation, four methods were investigated:

- the rating on a continuous discomfort scale,

- the method of constant stimuli,

- the method of limits,

- and the adjustment.

For relative evaluation, three methods were tested:

- the paired comparison,

- the matching,

- and the magnitude estimation.

For the rating on a continuous discomfort scale (Fotios, 2015), the subjects had to rate the discomfort glare produced by the two simuli, presented at three luminance levels, on a $10 \mathrm{~cm}$ continuous scale (from "not at all" to "extremely"). The luminance levels were $10 \mathrm{kcd} / \mathrm{m}^{2}, 58$ $\mathrm{kcd} / \mathrm{m}^{2}$ and $140 \mathrm{kcd} / \mathrm{m}^{2}$. HighMel at $58 \mathrm{kcd} / \mathrm{m}^{2}$ was repeated to study repeatability. Thus, seven stimuli were rated.

For the method of constant stimuli (Goldstein, 2010), the stimuli (LowMel and HighMel repeated twice) were presented six times at five different light levels and the subjects had to express if they felt discomfort or not. The five luminance levels were $5 \mathrm{kcd} / \mathrm{m}^{2}, 10 \mathrm{kcd} / \mathrm{m}^{2}, 24 \mathrm{kcd} / \mathrm{m}^{2}, 58$ $\mathrm{kcd} / \mathrm{m}^{2}$ and $140 \mathrm{kcd} / \mathrm{m}^{2}$. Hence 90 stimuli ( 3 stimuli $\times 6$ times $\times 5$ levels) were presented.

For the method of limits (Bargary, Jia and Barbur, 2015), the three stimuli (LowMel and HighMel repeated twice) were presented from three low anchors $\left(2 \mathrm{kcd} / \mathrm{m}^{2}, 3 \mathrm{kcd} / \mathrm{m}^{2}\right.$ and $\left.5 \mathrm{kcd} / \mathrm{m}^{2}\right)$ and three high anchors $\left(130 \mathrm{kcd} / \mathrm{m}^{2}, 145 \mathrm{kcd} / \mathrm{m}^{2}\right.$ and $\left.160 \mathrm{kcd} / \mathrm{m}\right)$. From the low anchors, the subjects were asked if they felt discomfort. If the answer was negative, the light level was increased by step by the experimenter. Then the same question was asked again and the light level was increased step by step until reaching the discomfort threshold. From the high anchors, the question was the same but the light level was decreased until reaching the comfort threshold.

For the adjustment procedure (Luckiesh and Guth, 1949; Kim, Han and Kim, 2009), the subjects directly adjusted the light level with a rotary control pad to reach the borderline between comfort and discomfort (BCD (Luckiesh and Guth, 1949)) from low and high anchors. Two ranges of luminance were proposed: $0-100 \mathrm{kcd} / \mathrm{m}^{2}$ and $0-140 \mathrm{kcd} / \mathrm{m}^{2}$. Twelve adjustments were done $(3$ stimuli $\times 2$ low anchors $\times 2$ high anchors).

For relative evaluation, the stimuli were judged by pair. We decided to present each stimulus during five seconds with a one-second break between the two stimuli of the pair.

For the paired comparison method (Scheir et al., 2016), the two stimuli (LowMel and HighMel) were presented at three luminance levels $\left(10 \mathrm{kcd} / \mathrm{m}^{2}, 58 \mathrm{kcd} / \mathrm{m}^{2}\right.$ and $\left.140 \mathrm{kcd} / \mathrm{m}^{2}\right)$. Each stimulus was compared to itself and to the others (in pair presentations) and subjects had to select which stimulus produced more discomfort (forced-choice method). Thirty-six pairs were presented ( 2 stimuli $\times 3$ levels $\left.)^{2}\right)$. HighMel at $58 \mathrm{kcd} / \mathrm{m}^{2}$ was used to study repeatability; thus the 11 pairs 
including this stimulus were repeated. For each of the 47 pairs, the observer could ask to repeat the pair as many times as needed.

For the matching (Kim, Han and Kim, 2009), the subjects had to adjust the light level of a stimulus to equalize its discomfort perception to the discomfort perception of a reference stimulus (adjustments were made from high and low anchors). LowMel was adjusted to match HighMel at $58 \mathrm{kcd} / \mathrm{m}^{2}$, HighMel was adjusted to match LowMel at $58 \mathrm{kcd} / \mathrm{m}^{2}$, LowMel was adjusted to match LowMel at $58 \mathrm{kcd} / \mathrm{m}^{2}$ and HighMel was adjusted to match HighMel at 58 $\mathrm{kcd} / \mathrm{m}^{2}$. The adjustment of HighMel to LowMel at $58 \mathrm{kcd} / \mathrm{m}^{2}$ and of LowMel to HighMel at 58 $\mathrm{kcd} / \mathrm{m}^{2}$ were repeated to study the repeatability. Thus six matchings were done. The first stimulus of the pair was the reference and the second was the adjusted one. The luminance range of the glare stimuli was $0-170 \mathrm{Kcd} / \mathrm{m}^{2}$, measured from the eye of the observer. As for the paired comparison, the observers could ask to repeat the pair as many times as needed.

For the magnitude estimation (Scheir et al., 2015), the two stimuli were presented at three luminance levels $\left(10 \mathrm{kcd} / \mathrm{m}^{2}, 58 \mathrm{kcd} / \mathrm{m}^{2}\right.$ and $\left.140 \mathrm{kcd} / \mathrm{m}^{2}\right)$. HighMel at $58 \mathrm{kcd} / \mathrm{m}^{2}$ was repeated to study repeatability. For each of the seven stimuli, subjects were asked to give a numerical estimate of the discomfort perception produced by a stimulus, comparing to the perception produced by LowMel at $58 \mathrm{kcd} / \mathrm{m}^{2}$ (discomfort numeric value of "100"). The numerical value of "0" was defined as "no discomfort at all". There was no upper limit. The first stimulus of the pair was the reference (LowMel at $58 \mathrm{kcd} / \mathrm{m}^{2}$ ) and the second was the estimated one.

Due to the number of tested methods and to limit subjects fatigue, the experiment was divided in two sessions of approximately one hour (absolute methods in the first session and relative methods in the second one). The order of the procedures within each session and the order of the stimuli within each procedure were counterbalanced to avoid any bias due to presentation order (unbalanced latin squares).

\subsection{Physiological experimental procedures}

The investigations about physiological measurements were focused on the link between the presence of discomfort glare and the variation of physiological signals (based on the observation of their variation during exposure to glaring and non-glaring stimuli).

Four physiological measurement devices were investigated:

- electrocardiography (ECG) - measurement of heart rate with an ECG patch from Micro Medical Device Inc. (Belkic, 1986)

- electroencephalography (EEG) - measurement of brain signals with an EEG headset Epoc+ (Emotiv) (Bargary et al., 2015)

- electromyography (EMG) - measurement of the intensity of the electrical activity on facial muscles near the eye with a Vitaport-4 digital recorder (Berman et al., 1994; Murray, Plainis and Carden, 2002)

- and pupillometry - measurement of the variation of pupil size with a Viewpoint eye tracker (Arrington Research Inc.) (Stringham, Fuld and Wenzel, 2004).

Due to the impossibility to equip the subject simultaneously with all these devices, the experiment was divided in two sessions, with the exact same protocol. In the first session, EMG, EEG and ECG were monitored. In the second one, pupil diameter and ECG were recorded. For each subject the whole experiment took approximately $2 \mathrm{~h} 30$. 

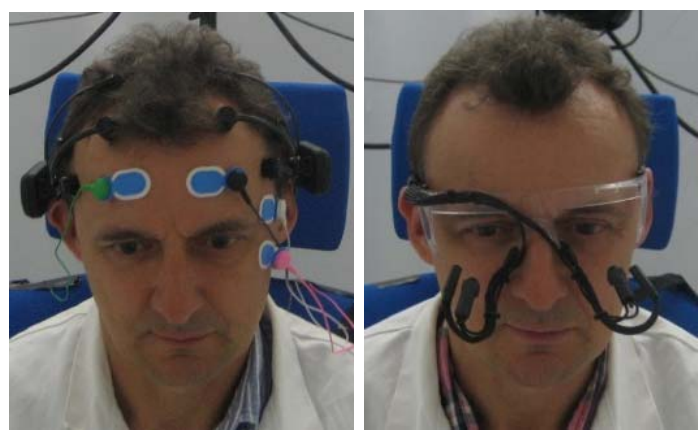

Figure 3 - Subject equipped with EMG, EEG and ECG (left) and with eye tracker and ECG (right)

The luminance of the glare source measured from the observer's eye position was set to 150 $\mathrm{kcd} / \mathrm{m}^{2}$ for both stimuli (Figure 2). To measure the range of pupil diameter for each subject a dark ambiance (no light) and a fully lit ambiance (all channels of the background sources at their maximum levels - vertical illuminance of 590 lux at the eye of the observer) were added. To investigate the range of influence of lighting stimuli on EEG data in comparison with other environmental stimuli, two sound sequences (one peaceful, one annoying) were also added to the discomfort glare sequences.

The experiment began with a dark period of 5 minutes (all sources turn off). Then the background sources were turned on during all the experiment (reference condition). This reference period lasted 3 minutes. Then each glare stimulus was presented during three minutes followed by a three minutes reference period. After that the fully lit period lasted 2 minutes and finally the two sounds were presented during 2 minutes each under the reference lighting. The order of the presentation of the two glare sources and the two sounds were counterbalanced between the observers.

\section{Results}

\subsection{Psychophysical experimental procedures}

Thirty-seven subjects participated to the psychophysical experiment, 15 males and 22 females. Ages ranged from 20 to 25 years old, with a mean at 22 years old and a standard deviation of 1.2 years old.

Before analyzing the data, their reliability was checked. The answers of two subjects were deleted because their discomfort thresholds were higher than the proposed values and this would have been a problem in particular for magnitude estimation and matching. Thus the answers of 35 subjects were analysed for the seven psychophysical procedures.

Mixed models analysis were employed to study the effects of luminance levels, SPDs, anchors or ranges. Repeatability of the procedures was also investigated comparing the conclusions provided by the two sets of data including one stimulus or replacing it by its corresponding repeated stimulus. We considered that a $p$-value inferior to 0.05 indicated a significant effect of the corresponding factor.

For the rating on a continuous discomfort scale, the mixed model showed an influence of the luminance levels whatever the subset used and an effect of the SPD just for one subset. Thus, the results obtained with this procedure were not repeatable.

For the method of constant stimuli, the answers for each subject were gathered and a percentage of positive answers was calculated for each light level. The psychometric function of the subject was thus obtained, leading to the discomfort threshold of the subject. The mixed model applied on the discomfort threshold of all subjects concluded that the SPD were not significant factors (same conclusion about SPD for both subset, thus repeatable conclusion).

For the method of limits, the mixed model applied on the discomfort thresholds concluded that the SPD and the anchors have an influence (same conclusion for both subsets, thus repeatable conclusion). 
For the adjustment procedure, the mixed model showed that the there was an influence of the anchor whatever the subset used but significant effects of the SPD and the range only for one subset. Thus the results obtained with this procedure were not repeatable.

For the paired comparison method, no order of presentation effects was found. Luminance levels and SPDs were significant factors (same conclusion for both subsets, thus repeatable conclusion).

For the matching, the null condition was not verified and there was an effect of presentation order: subjects did not match a light stimulus to itself at an equivalent light level (the ratio between the two light levels was significantly different from unity); the ratio between two glare stimuli was significantly different depending of the stimulus which was the reference of the pair. The SPD is concluded as a significant factor differently depending on the subset (not repeatable conclusions).

For the magnitude estimation the mixed model showed that there was a significant influence of the luminance levels and the SPDs whatever the subset used (repeatable conclusions).

\subsection{Physiological experimental procedures}

Eight males participated to the physiological experiment. Ages ranged from 21 to 55 years old, with a mean at 27.5 years old and a standard deviation of 10.5 years old. The aim of this experiment was to explore physiological procedures and to qualitatively observe if the lighting conditions influenced the variation of physiological measures. Hence, for this part, the measurements were analysed for each subject separately.

Different analyses were produced from the physiological data: variations in pupil size, variations in heart rate, wavelet analysis for the EEG and EMG data. The wavelet analysis was performed with EEGLAB programs (Grandchamp, 2012), to calculate time-frequency data. The wavelet data were integrated on frequency domains (alpha-band, etc.) or time domains (LowMel stimulus sequence, etc.). The first finding was that whatever the physiological measure used, there were differences between subjects' physiological data.

For the ECG measure, the evolution of the metrics based on the heart recording (heart rate, LFA/HFA, etc.) could not be related to the presence of the experimental stimuli (see for example Figure 4).

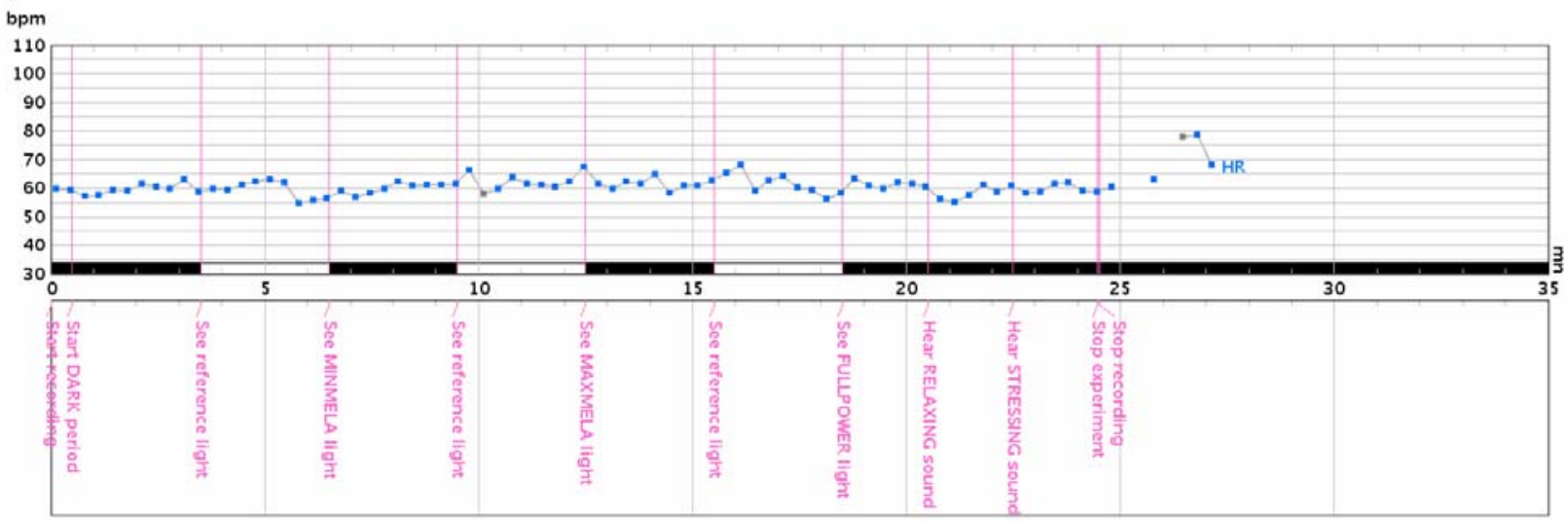

Figure 4 - Example of heart rate (bpm) recording for one subject during the experiment

For the EEG measure, no significant change was observed for the two glare stimuli on the 14 analysed electrodes. An increase of the integrated signals on beta/gamma-band was observed during the fully lit ambiance, and the two sound sequences (depending on the electrodes and the subjects).

For the EMG measure, no significant change was observed for the two glare stimuli. An increase of the signals was observed during the fully lit ambiance for six subjects. 
For the pupil size, significant variations in pupil diameter were observed between dark ambiance, reference ambiance, fully lit ambiance and glare stimuli but not between the two glare stimuli. Pupils were more constricted for the fully lit ambiance than for the glare stimuli. Subjects indicated that the two glare stimuli did not produce the same discomfort glare perception, however, the differences of pupil diameter that could be observed between the two glare stimuli were about the same range of variation as the temporal fluctuations of the pupil diameter occurring through the whole recording. Hence no conclusion correlating the difference in discomfort between the two glare stimuli and the variation in pupil size could be made.

One interesting point is that EEG, EMG and pupil size seemed more sensitive to an increase in luminance of the whole visual field than to an increase in luminance of a localised light source providing the same vertical illuminance level at the eye position. Indeed, the glare stimuli and the fully lit ambiance provided similar illuminance levels (590 lux for the fully lit ambiance and 526 lux for the glare stimuli measured at the eye of subject).

While discomfort glare was present in this experiment, none of the physiological measurement devices provided an indicator of its perception. With our experimental conditions, representative of typical indoor lighting, it seems difficult to obtain discriminant physiological responses to characterise discomfort glare. Such measurement tools seem more appropriate to study the influence of lighting in the whole field of view or might be more relevant to study higher discomfort glare perception (lower light ambiance or higher glare light levels).

\section{Conclusions}

None of the tested physiological measurements produced relevant information concerning the potential discomfort glare perceived in our experimental conditions. There is a need to further investigate these procedures for discomfort glare characterisation in other conditions (dark or photopic ambiance, localised stimuli or covering the whole visual field). As mentioned in (Mainster and Turner, 2012), interdisciplinary collaborations between engineering and neuroscience should be encouraged and would benefit both communities.

Psychophysical data were analyzed with mixed models and led to conclusions about the discomfort provided by the stimuli (luminance level, spectral effect) but also other effects from experimental biases. Such biases were highlighted for some psychophysical procedures (range bias, anchor bias, null condition, presentation order). Anchor bias was demonstrated in the adjustment procedure and the method of limits: subjects adjust their discomfort threshold higher when starting from the maximum of the range, in comparison of starting from the minimum. On the contrary, this effect was not significant in the matching procedure, maybe because subjects match their threshold to a reference light. Range bias was found for the adjustment procedure: the adjusted threshold increases with the maximum limit of the range. For the matching, the null condition was not verified and there was an effect of presentation order. Some of these experimental biases can also occur in spatial brightness experiments, as mentioned in $\mathrm{CIE}$ 212:2014 (CIE, 2014). Besides, some procedures did not provide the same glare evaluations for the repeated stimuli. Based on these results, we recommend to use three psychophysical procedures to evaluate discomfort glare at photopic levels (one absolute and two relative methods): the method of constant stimuli, the paired comparison and the magnitude estimation.

\section{References}

Bargary, G. et al. (2015) 'Cortical hyperexcitability and sensitivity to discomfort glare', Neuropsychologia, 69, pp. 194-200. doi: 10.1016/j.neuropsychologia.2015.02.006.

Bargary, G., Jia, Y. and Barbur, J. L. (2015) 'Mechanisms for Discomfort Glare in Central Vision', Investigative Ophthalmology \& Visual Science, 56(1), pp. 464-471. doi: 10.1167/iovs.14-15707.

Belkic, K. (1986) 'Light stress and the cardiovascular system: the glare pressor test', Ergonomics, 29(4), pp. 563-568. doi: 10.1080/00140138608968291.

Berman, S. et al. (1994) 'An objective measure of discomfort glare', Journal of the Illuminating Engineering Society, 23(2), pp. 40-49. 
CIE (1995) CIE 117:1995 Discomfort glare in interior lighting. Vienna: CIE.

CIE (2013) CIE 205:2013 Review of lighting quality measures for interior lighting with LED lighting systems. Vienna: CIE.

CIE (2014) CIE 212:2014 Guidance towards best practice in psychophysical procedures used when measuring relative spatial brightness. Vienna: CIE.

CIE (2015) CIE 170-2:2015 Fundamental Chromaticity Diagram with Physiological Axes - Part 2: Spectral Luminous Efficiency Functions and Chromaticity Diagrams. Vienna: CIE.

CIE (2017) elLV - International Lighting Vocabulary. Available at: http://eilv.cie.co.at/ (Accessed: 19 June 2017).

CIE (2018a) CIE 15:2018 Colorimetry. 4th ed. Vienna: CIE.

CIE (2018b) CIE S 026/E:2018 CIE system for metrology of optical radiation for ipRGCinfluenced responses to light. CIE (S 026).

Fotios, S. (2015) 'Research Note: Uncertainty in subjective evaluation of discomfort glare', Lighting Research and Technology, 47(3), pp. 379-383. doi: 10.1177/1477153515574985.

Geerdinck, L. M. et al. (2016) 'Discomfort glare of non-uniform luminaires - A literature review', in Proc. of 4th CIE Expert Symposium on Colour and Visual Appearance. Prague, pp. 247256.

Grandchamp, R. (2012) Electroencéphalographie et Interfaces Cerveau-Machine: nouvelles méthodes pour étudier les états mentaux. Université de Toulouse, Université Toulouse IIIPaul Sabatier. Available at: http://thesesups.ups-tlse.fr/2020/ (Accessed: 15 September 2017).

Kim, W., Han, H. and Kim, J. T. (2009) 'The position index of a glare source at the borderline between comfort and discomfort (BCD) in the whole visual field', Building and Environment, 44(5), pp. 1017-1023. doi: 10.1016/j.buildenv.2008.07.007.

Luckiesh, M. and Guth, S. K. (1949) 'Brightness in visual field at borderline between comfort and discomfort (BCD)', Illuminating Engineering, 44(11), pp. 650-670.

Mainster, M. A. and Turner, P. L. (2012) 'Glare's Causes, Consequences, and Clinical Challenges After a Century of Ophthalmic Study', American Journal of Ophthalmology, 153(4), pp. 587-593. doi: 10.1016/j.ajo.2012.01.008.

Murray, I., Plainis, S. and Carden, D. (2002) 'The ocular stress monitor: a new device for measuring discomfort glare', Lighting Research and Technology, 34(3), pp. 231-242. doi: 10.1191/1365782802lt046oa.

Scheir, G. et al. (2015) 'Effect of luminance contrast on the perception of discomfort', in Proceedings of the 28th CIE session. Proc. of 28th CIE conference, Manchester, pp. 18701876.

Scheir, G. et al. (2016) 'A psychophysical model for visual discomfort based on receptive fields', Lighting Research and Technology. doi: 10.1177/1477153516660606.

Stringham, J. M., Fuld, K. and Wenzel, A. J. (2004) 'Spatial Properties of Photophobia', Investigative Opthalmology \& Visual Science, 45(10), p. 3838. doi: 10.1167/iovs.04-0038. 